\title{
'Agenda-setting' de medios en la guerra contra las drogas
}

\author{
Oscar Mario Miranda VillanUeVA \\ omiranda83@gmail.com \\ Tecnológico de Monterrey, Campus Monterrey. \\ Centro de Investigación en Comunicación e Información (CINCO) México \\ Ángel IGLESIAS ORTIZ \\ ai81292@uta.fi \\ Universidad de Tampere. Tampere Peace Research Institute (TAPRI) Finlandia
}

Recibido: 29 de marzo de 2014

Aceptado: 5 de septiembre de 2014

\section{Resumen}

El presente escrito intenta dar luz a las temáticas relacionadas a la guerra contra las drogas en México, y a la frecuencia con la que se cubren en la prensa internacional. Se utilizaron dos enfoques distintos para su abordaje: Agenda-setting y la domesticación. La información se recabó en tres periódicos internacionales y uno nacional: The Guardian de Inglaterra, The New York Times de Estados Unidos, El País de España, y El Universal de México. Se realizó un análisis de contenido de las historias periodísticas reportadas alrededor del período de transición política del 2012 en el gobierno Mexicano. Los resultados evidenciaron que si bien hay una persistencia en la cantidad de noticias, también se registra una ligera diferenciación en la tendencia de las historias que cada uno de los periódicos reporta.

Palabras clave: Agenda-setting de Medios, Cultura del Mundo, Domesticación, Guerra contra las Drogas, Neo-institucionalismo

\section{Media Agenda-setting on War on Drugs}

\begin{abstract}
The present paper attempts to shed light on the issues related to the war on drugs in Mexico, and their frequency of coverage in the international press. Agenda-setting and domestication are two different approaches used to address them. The information was collected in one national and three international newspapers: The Guardian of England, The New York Times of the United States, El País of Spain, and El Universal of Mexico. A content analysis of news stories in the political transition period of the 2012 in the Mexican government was conducted. The results showed that while there is persistence in the number of news stories from the change of government, there is also a slight difference in the trend of themes that each of the newspapers reported.

Keywords: Media Agenda-setting, World Culture, Domestication, War on Drugs, Neo-institutionalism

\section{Referencia normalizada}

MIRANDA VILLANUEVA, Óscar Mario e IGLESIAS ORTIZ, Ángel (2015): ““Agenda-setting' de medios en la guerra contra las drogas". Estudios sobre el Mensaje Periodístico. Vol. 21, Núm. 1 (enerojunio), págs.: 403-420. Madrid, Servicio de Publicaciones de la Universidad Complutense.
\end{abstract}

Sumario: 1. Introducción. 2. Marco teórico. 3. Datos y metodología. 4. Resultados; 4.1. Diferencias y similitudes en temáticas generales; 4.2. Diferencias y similitudes de las temáticas generales en el período de transición política del 2012 en el gobierno mexicano; 4.3. Diferencias y similitudes en temáticas específicas y vinculación del término "guerra contra las drogas" a las realidades políticas y sociales nacionales de los periódicos analizados. 5. Conclusiones. 6. Referencias bibliográficas. 


\section{Introducción}

Las cuestiones de la seguridad y el tráfico de drogas en México han atraído la atención mundial debido a sus implicaciones en los planos nacional, regional e internacional. El tráfico de drogas y las actividades delictivas relacionadas han alcanzado presencia global, convirtiendo a esta actividad delictiva en una amenaza para muchos países. El término "guerra contra las drogas" se convirtió en la expresión para describir las políticas de seguridad del gobierno de México $^{1,2}$ y el propio conflicto. El término fue ampliamente utilizado públicamente sobre todo durante el período de 2006-2012 en los medios de comunicación mexicanos, pero también en los medios de comunicación internacionales.

A diferencia de estudios previos en los que se enfatiza la atención en la proporción de notas que cumplen con una aseveración de ética profesional y sensacionalismo periodístico (Iglesias, 2013; Martínez, Lozano, y Rodríguez, 2012; Meyer y Miranda, 2013; Sánchez, 2013), el presente trabajo se enfoca en identificar el tipo de temáticas que han sido incluidas en la cobertura de medios extranjeros respecto al fenómeno como tal, y su cobertura mediática. En ese sentido, el término "guerra contra las drogas" se entiende como una política pública establecida por el estado para el control del tráfico ilegal de productos naturales y sintéticos considerados nocivos para la salud. Por lo tanto, se toma como un modelo de política pública, o idea, que fluye de un lado a otro implementándose de manera distinta en cada contexto.

En el contexto del intercambio global de ideas e información, este trabajo aborda la cobertura realizada por los periódicos El País, The New York Times y The Guardian sobre el conflicto de las drogas en México ${ }^{3}$ en un rango de tiempo de 12 meses divido en dos períodos ${ }^{4}$. Para ello, este trabajo considera dos marcos teóricos para interpretar el fenómeno: Agenda-setting (Benton y Frazier, 1976; Guo, Tien Vu y McCombs, 2012; Funkhouser y McCombs, 2001; Kim y McCombs, 2007; McCombs y Ghanem, 2001; McCombs y Shaw, 1972; Renita, McCombs, Shaw, y Weaver, 2009; Scheufele y Tewksbury, 2007), y el marco de la domesticación (Alasuutari, Qadir, y Creutz, 2013; Clausen, 2004; Dai y Hyun, 2010; Gurevitch, Levy, y Roch, 1991; Liebes, 1992).

1 Reconocimientos: Al Consejo Nacional de Ciencia y Tecnología (CONACYT) por el apoyo económico otorgado para la elaboración de investigación científica a nivel doctoral. Al Centro de Investigación en Comunicación e Información (CINCO), del Tecnológico de Monterrey, por facilitar las condiciones para consolidar esta investigación. Al Grupo de Investigación en Tampere para la Sociología Cultural y Política (TCuPS) por la retroalimentación en su seminario. Y a los colegas y los amigos que a lo largo de esta investigación han logrado moldear el proyecto.

2 La táctica más polémica era desplegar miles de agentes de seguridad en las ciudades donde los cárteles de la droga estaban luchando entre sí.

3 Al mismo tiempo, consideramos las mismas historias noticiosas del periódico mexicano $\mathrm{El}$ Universal, con la intención de comparar las temáticas y coberturas sobre las mismas cuestiones.

4 Del 1 de junio al 30 de noviembre de 2012, y del 1 de diciembre de 2012 al 31 de mayo de 2013. 
Agenda-setting, por un lado, se refiere al contenido e influencia de los medios de comunicación en dos niveles diferentes: el primer nivel en relación con los temas u objetos, y el segundo nivel en relación con los atributos o encuadres (Weaver, McCombs, y Shaw, 2004). Bajo el primer nivel, este enfoque se centra en el tipo de asuntos reportados en los medios de comunicación. El objetivo es reconocer el tipo de temática entre el contenido de las noticias. Bajo el segundo nivel, por otro lado, la preocupación es identificar la manera en que esas cuestiones se enmarcan. El marco de la domesticación, por otro lado, se refiere al contenido de los medios de comunicación como la forma en que los eventos globales se adaptan a la situación inmediata $(\mathrm{Gu}-$ revitch, Levy, y Roch, 1991) y a través del tiempo por distintos actores (Qadir y Alasuutari, 2013; Alasuutari, Qadir, y Creutz, 2013).

La idea inicial acerca de la intensidad con la que se cubre periodísticamente una política pública implica pensar que dicha intensidad va a ser una constante hasta su consolidación y a pesar de los cambios gubernamentales. Para hacer una contribución a la discusión de estas temáticas, el presente escrito se plantea tres objetivos. Primero, nuestro interés es identificar temáticas generales y particulares en las historias noticiosas de los tres periódicos internacionales en relación al conflicto de seguridad y narcotráfico en México. Al combinar los marcos espaciales y temporales, este ejercicio confronta las similitudes y las diferencias entre las noticias que informan de un evento distante en los medios internacionales. La discusión, por lo tanto, aborda el debate acerca de la homogeneidad y heterogeneidad en el flujo global de información. El análisis dará evidencias acerca de cómo este tema en particular se ha reportado, y cuáles son las temáticas e intereses editoriales en las que enfocan su cobertura los periódicos.

El segundo objetivo es identificar diferencias y similitudes de las temáticas generales en el período de transición política. Esto tiene que ver con los cambios que tomó el nuevo gobierno desde el 1 de diciembre de 2012. El gobierno elegido implementó una nueva estrategia de seguridad y comunicación en relación con el tráfico de drogas y la violencia criminal. Por lo tanto, el término la "guerra contra Drogas" fue excluido del discurso oficial. El análisis trata de identificar si hay cambios en la cobertura realizada por estos periódicos internacionales durante los períodos seleccionados. Los resultados se comparan con el periódico mexicano.

$\mathrm{Y}$ el tercer objetivo es identificar diferencias y similitudes de las temáticas específicas, y si el término "guerra contra las drogas" está vinculado a las realidades políticas y sociales nacionales de los periódicos analizados. En este sentido, la discusión se coloca en el escenario global-local donde el conflicto de seguridad y narcotráfico en México, como conflicto local y distante, atrae la atención de los medios de comunicación internacionales y los actores locales.

La organización de este artículo se describe a continuación. En la siguiente sección se examinan los antecedentes del problema, y se describe la revisión de la literatura sobre el tema. La sección de datos y metodología se centra en describir el tipo de datos y los pasos seguidos para su análisis. La sección de resultados apunta principalmente a dar respuestas a los objetivos establecidos. Y, por último, la sección de discusión relaciona los hallazgos de esta investigación con los resultados encontrados en la revisión de la literatura, y los vincula a la discusión teórica contemporánea sobre el fenómeno. 


\section{Marco teórico}

De acuerdo con Gary Fischer (2006: 4-5), el término "guerra contra las drogas "se puede remontar a la administración de Richard Nixon a principios de 1970 con las primeras medidas tomadas por el gobierno de EE.UU.: la creación de la Oficina de Acción Especial para la Prevención del Abuso de Drogas y la Agencia de Lucha Contra las Drogas (DEA). Bajo Ronald Reagan la Oficina de Política Nacional de Control de Drogas (ONDCP) fue creada con el fin de reducir el uso y la disponibilidad de drogas ilícitas.

La analogía de la "guerra" ha sido el lugar común donde las estrategias sobre el consumo y el tráfico encontraron un referente contextual. Por lo tanto, apelar a la noción de guerra impone una lógica que implica la esencia de confrontación. Por ejemplo, en los aspectos legales y de seguridad, el término implica hacer frente a las actividades de tráfico de drogas a través de las fuerzas de seguridad, reforzando las leyes y los controles contra esta actividad delictiva o de lavado de dinero. En el aspecto social, las políticas y los programas para controlar y reducir el uso de drogas ilícitas complementan las estrategias anteriores.

La premisa de este trabajo tiene que ver con los cambios en las estrategias de seguridad y de comunicación entre los dos periodos presidenciales ${ }^{5}$, y entender cómo se reflejó en la cobertura informativa del problema. El plan para combatir abiertamente los cárteles de la droga con la policía y las fuerzas armadas, y las constantes referencias discursivas para participar en el combate contra las organizaciones criminales o luchar por la seguridad nacional trajo el término " guerra contra las Drogas "(War on Drugs) como eslogan en medios de comunicación y el uso popular.

La principal diferencia entre las dos administraciones es que la actual no utiliza más dicho término en su discurso oficial. Es decir, no forma parte de los nuevos temas de las estrategias de comunicación relacionados con las reformas políticas y económicas prevalecientes en la agenda pública nacional. Esto supone también un posible cambio en la cobertura noticiosa de los medios de comunicación mexicanos. Los hechos relacionados al tráfico de drogas no son seguidos tan a detalle como en la administración presidencial anterior. Por tal motivo, el interés de este escrito es hacer un censo en ambos períodos para examinar si la nueva estrategia también se experimenta en los informes de la prensa internacional.

Al colocar la atención en un modelo de política pública o estrategia del gobierno mexicano, se posibilita entender y discutir dicho fenómeno desde distintas perspectivas teóricas. En este caso se utilizan dos aproximaciones teóricas que discuten el fenómeno desde la comunicación y la esfera pública, el consumo, y el flujo e intercambio de información dentro del contexto global. Se trata de las perspectivas de agenda-setting, y domesticación. La perspectiva de agenda-setting ayuda a identificar los textos y los contextos del hecho noticioso. Es decir, el posicionamiento de las temáticas que se desprenden de una idea en los debates mediáticos, y las maneras en que se difunden en los medios de comunicación. Por otro lado, el marco de la do-

5 El primer período presidencial es de diciembre de 2006 a noviembre de 2012, la actual administración comenzó el 01 de diciembre 2012. 
mesticación ayuda a entender la manera en que esa idea fluye y es consumida de un actor a otro en distintas localidades. Finalmente, también es posible discutir el fenómeno desde una perspectiva neo-institucionalista al confrontar los conceptos de cultura del mundo y diversidad cultural.

El enfoque de Agenda-setting postula tres niveles distintos para analizar el mensaje de los medios (Benton \& Frazier, 1976; Guo, Tien Vu, y McCombs, 2012). El mensaje como objeto referencial es influenciado, influye y es utilizado por distintos actores y en distintas circunstancias (Weaver, McCombs, y Shaw, 2004). El primer nivel se refiere a los asuntos o las temáticas que son enfatizadas desde los medios. Este nivel aborda la relación de una idea a distintos hechos o temáticas en particular y su presentación a la opinión pública. Bajo esta perspectiva, la idea "guerra contra las drogas" está asociada a distintas temáticas en los medios noticiosos. Por lo tanto, lo importante es identificar cuáles son esos hechos o temáticas a los que se le relaciona y qué incidencia tienen en la cobertura informativa y en la coyuntura política.

El segundo nivel se refiere a los atributos o encuadres del hecho noticioso. Se refiere a la manera en que esos hechos o temáticas se encuentran constituidos, y la manera en que el medio de comunicación discute el hecho como tal. Esta teoría identifica dos tipos de atributos de las temáticas: los cognitivos y los afectivos. Los cognitivos se refieren a atributos minúsculos que no constituyen una mayor implicación. Pero los afectivos son atributos mayores adjudicados y que representan una evaluación del hecho, temática y hasta del actor (persona o institución) relacionados al hecho noticioso. Estos últimos se consideran encuadres desde que modifican el sentido o el significado original del tema principal (McCombs y Ghanem, 2001).

El segundo nivel de agenda-setting se acerca a la propuesta del framing, o encuadre. Existe un considerable debate entre las limitaciones de agenda-setting y framing como aproximaciones teóricas. El debate considera que ambas perspectivas hablan de ciertos atributos colocados al hecho noticioso. No obstante, Renita et al. (2009) argumentan que si bien ambos proponen criterios de evaluación de los encuadres, son esos mismos criterios los que distinguen a uno y otro en la manera de proceder.

Agenda-setting se distingue por tener una mayor accesibilidad a los encuadres del hecho noticioso de algún tema en específico, pero poca profundidad en los análisis de esos encuadres. Mientras que a framing en ocasiones se le cuestiona la pertinencia de sus análisis. Liebes (1992), por ejemplo, analiza los encuadres en las televisiones estadounidense e israelí dentro de los contextos de la intifada y la guerra del golfo. En ellas identifica seis encuadres distintos que a su ver son claros en la manera de reportar las noticias: escisión, desinfección, igualar, personalización, demonización y contextualización. Sin embargo, en dicha investigación nunca se contextualiza a que temáticas del hecho noticioso corresponden los encuadres. Simplemente se realiza una distinción en la posición del periodista en la manera de reportar las noticias.

El último nivel tiene sus orígenes en un escrito de Brenton y Frazier (1976) en el cual se teoriza respecto a los tres niveles. No obstante, a últimas fechas este nivel ha tenido revuelo bajo la autoría de uno de sus principales exponentes: Maxwell McCombs (Guo, Tien Vu, y McCombs, 2012). El tercel nivel de agenda- setting se enfoca en las posturas respecto a una determinada temática dentro del hecho noticioso. 
Se centra en analizar los pros y los contras de un tema, los actores implicados en el tema, y si hay o no una correspondencia directa o efecto en la opinión pública acerca de los asuntos en el hecho noticioso. Es decir, no solamente se limita en analizar la homogeneidad de los temas en distintos medios noticiosos, sino también si esos temas se encuentran en la agenda de la opinión pública y la correspondencia de las posturas, en pro y en contra, entre ambos.

Esta aproximación, por otro lado, también menciona que el mensaje es influenciado, influye y es utilizado por distintos actores y en distintas circunstancias. En este sentido, hay tres actores y/o eventos que se distinguen como los principales influenciadores de la agenda de un medio: los presidentes y sus relaciones públicas, las campañas políticas, y la agenda de otros medios. La agenda de un medio puede influir en la percepción y el comportamiento del ser humano. Y en las políticas públicas relacionadas al tema. Además, puede ser utilizada como un mecanismo de orientación, por ejemplo, para distinguir un evento en relevancia, en los momentos de indecisión o por un simple factor educativo. No obstante, puede también ser obstruida a causa de la experiencia misma del individuo.

A pesar de que hay evidencia empírica que sostiene una débil correspondencia entre la agenda de los medios y sus efectos en la audiencia (McLeod, Becker, \& Byrnes, 1974), hay numerosos estudios que sostienen lo contrario (Funkhouser y McCombs, 2001; Kim y McCombs, 2007; McCombs y Shaw, 1972; Sei-Hill, Scheufele, y Shanahan, 2002; Tan y Weaver, 2013; Valenzuela y McCombs, 2007; Tan y Weaver, 2013). Todos han ahondado, en mayor o menor dimensión y en distinto contexto y temporalidad, la correspondencia entre la agenda de los medios y las opiniones de la audiencia. La mayoría ha delimitado la estrecha relación entre los temas y los atributos de los medios con lo que piensa la opinión pública; en referencia al primer y el segundo nivel. Pero rara vez se han atestiguado los efectos de los medios en los juicios evaluativos de la audiencia respecto a lo que consumen; en referencia al tercer nivel.

El postulado de la domesticación, por otro lado, no cuestiona el inobjetable impulso globalizador en cuanto a contenidos en la oferta noticiosa, pero reconoce la capacidad y necesidad del medio local de resistir y discernir mediante procesos de apelación al referente cultural inmediato. La globalización de las noticias, mediante la televisión satelital y el internet, han dado un giro cuantitativo y cualitativo al flujo y oferta noticiosa. El impacto de este proceso irremediablemente lleva a la discusión en cuanto a la convergencia y la diversidad del contenido. La cobertura de hechos noticiosos globales ha implicado una convergencia en las prácticas profesionales y ha desarrollado cierta similitud en valores y trato informativo en las agencias nacionales. (Gurevitch, et al., 1991: 201). El desarrollo tecnológico y el creciente acceso a flujos de información global han revolucionado la experiencia mediática cotidiana. Consecuentemente, se ha problematizado el uso e interpretación de la información dentro del contexto global-local.

Desde el marco de la domesticación, el texto mediado por las noticias es analizado a través del espacio y el tiempo. En su estudio acerca de las salas de prensa mundial, Gurevitch, Levy y Roch (ibid) identifican dos formas distintas en las que se realiza el 
proceso de domesticación en las noticias desde el punto de vista del espacio. Por un lado, se encuentra la manera en que acontecimientos lejanos son colocados en marcos comprensibles, atractivos y relevantes para el público nacional. Por otro lado, está la manera en que se construyen significados de los eventos interpelando a la cultura y la ideología dominante de las sociedades a las que sirven. Todos los estudios a este respecto (Clausen, 2004; Dai y Hyun, 2010; Eide y Ytterstad, 2011; Handley y Ismail, 2010; Ismail, 2010; Lacasse y Forster, 2012; Lee, Pan, Chan, y So, 2001; Nossek, 2004) se enfocan en contribuir al conocimiento de la manera de reportar un hecho noticioso para la audiencia local desde el ángulo del espacio.

Desde la instancia del tiempo, Qadir y Alasuutari (2013) y Alasuutari, Qadir y Creutz (2013) identifican maneras distintas en las que se realiza el proceso de domesticación en las noticias. Para ello estos autores utilizan periodos de tiempo distintos y revisan las implicaciones de los actores implicados en la construcción de las noticias como herramientas del proceso de domesticación. Analizan la cobertura de un solo fenómeno en momentos distintos. Apelando a la manera en que una categoría de actores coloca acontecimientos lejanos en marcos comprensibles y relevantes a su realidad en yuxtaposición con otra categoría de actores en el tiempo. Así, el argumento se construye a partir de la domesticación de ideas globales por actores locales. Estos trabajos se enfocan a la mediación del significado mediante la particularización y la interpretación compartida en un espacio cultural.

Esta perspectiva nos lleva directamente a los debates dentro del ámbito cultural y del intercambio de ideas y significados, y el posterior uso y reinterpretación de éstos mismos dentro de la dualidad global-local. El marco de globalización sirve como escenario donde se problematizan los procesos políticos, económicos, sociales y culturales de alcance mundial. Diferentes posturas polemizan acerca de las consecuencias de estos procesos en la vida cotidiana de cualquier persona en el mundo. La creación y posible reafirmación de una conciencia global directamente ligada a las problemáticas políticas y sociales es entendida como consecuencia del proceso de globalización (Robertson, 1992).

La esfera cultural no está exenta de los debates relacionados con la globalización. La tensión entre centros de producción cultural global y local, las formas y contenidos de cultura popular, programas de televisión o páginas de internet y los consecuentes procesos de homogenización y diversificación en la producción y consumo de los contenidos han causado el debate conceptual. Conceptos como el de centro-periferia (Wallerstein, 2007), flujos y escenarios (Appadurai, 1990), o cultura del mundo (Lechner y Boli (2005) intentan dar una explicación dentro del contexto cultural global.

En específico, académicos como Lechner y Boli (2005) en su obra Cultura del Mundo: Orígenes y Consecuencias realizan un recorrido de las distintas aproximaciones para el estudio de la cultura del mundo. En ella confrontan la cultura del mundo con el concepto de diversidad cultural. En su exposición describen las bases de estudio de la cultura del mundo sin dejar de lado las implicaciones que la diversidad cultural, propiamente dicha, genera a partir de su desenvolvimiento e interacción con otros elementos. Una de las aproximaciones que describen estos autores se refiere al 
modelo macro antropológico; relacionado a Appadurai. En él, "la cultura del mundo no aparece como una sola sustancia producida por la sociedad mundial, sino que es el conjunto de procesos mediante los cuales se organiza la diversidad a nivel mundial" (p. 55).

No son las instituciones mundiales las únicas que definen a la cultura del mundo. Sino también el conjunto de procesos que organizan a la diversidad de forma global. $\mathrm{O}$ visto desde otro ángulo, no es solamente la diversidad cultural organizada la que define la cultura del mundo, sino también la sociedad mundial que genera las condiciones para ligar lo global con lo local. Las instituciones, desde esta aproximación, se mantienen como las definidoras del $y o^{6}$. Sin embargo, no son las únicas que lo hacen. En el conjunto de procesos del que habla la perspectiva macro antropológica, se alude al individuo como el gran facilitador del yo a través de las instituciones. De tal forma que él/ ella es quien logra construir su identidad a través de una serie de procesos en intrínseca interacción con la sociedad que le rodea.

En el contexto del flujo de ideas a través de las historias noticiosas, se puede discutir la cultura del mundo o la diversidad cultural en la proporción de temáticas similares y en la manera en que esas temáticas se adaptan de lo global a lo local. En ese sentido, la homogeneidad y la heterogeneidad en las temáticas en distintos periódicos darán la pauta para discutir una cultura del mundo o una diversidad cultural respectivamente. Por otro lado, la manera en que estas temáticas se domestican posibilitará discutir si existe o no una cultura del mundo o si se debate el tema de la diversidad cultural en el hecho noticioso.

\section{Datos y metodología}

En esta sección se presentan y explican los datos recopilados. El interés en la prensa internacional surge de la mínima disponibilidad de estudios sobre la situación del narcotráfico en México fuera de la prensa nacional. Este caso de estudio complementa el interés de discutir la manera en que las noticias extranjeras se reportan y transmiten en distintos lugares. Tres periódicos internacionales fueron seleccionados de países que procuran las noticias de México: The New York Times de EE.UU., The Guardian del Reino Unido y El País de España. Y un periódico local fue seleccionado para contrastar los anteriores: El Universal de México.

El universo de la muestra está compuesto por todas las historias relacionadas con la guerra contra las drogas en México en los tres periódicos mencionados anteriormente. Las palabras clave y frases que operaron de mejor manera fueron: "El tráfico de drogas en México", "La guerra de México contra las drogas", y "Narcotráfico en México". Ninguna historia particular fue dejada de lado, artículos, editoriales, entrevistas, reportajes y notas, fueron tomadas en cuenta para efectos de esta investigación. Aunque la recolección de datos no se redujo a ciertas palabras en particular, principalmente tres frases funcionaron dependiendo del periódico en cuestión.

\footnotetext{
${ }^{6}$ En referencia al concepto de identidad
} 
La primera frase, "el tráfico de drogas en México", funcionó principalmente para recoger los datos de The New York Times. "La guerra de México contra las drogas " se utilizó principalmente en The Guardian. Y "Narcotráfico en México" arrojó buenos resultados de búsqueda en El País. Sin embargo, ninguna de ellas sólo se utilizó para un periódico en particular. Todas las entradas con su correspondiente traducción al inglés o español fueron colocadas como entradas entre los distintos periódicos.

La técnica de investigación utilizada en esta investigación fue el análisis de contenido (Krippendorff, 2004; Riffe, Lacy, \& Fico, 2005). Esta técnica fue empleada para confrontar la proporción de noticias relacionadas a la guerra contra las drogas en México en la prensa internacional. Dado que no había suficiente información relacionada con este tema en particular, se decidió abordarlo desde una perspectiva deductiva. Por lo tanto, todas las categorías se construyeron sobre la base de los datos recogidos.

Se hizo un censo para recopilar la información de los periódicos (Hernández, Fernández-Collado, y Baptista, 2006). Se consideraron todas las noticias relacionadas con la guerra contra las drogas en México en los periodos de tiempo establecidos: del 1 de junio al 30 de noviembre de 2012, y del 1 de diciembre de 2012 al 31 de mayo de 2013. El primer período abarca los últimos seis meses del presidente Felipe Calderón, en los que el término la Guerra contra las Drogas fue ampliamente utilizado, cuando las estrategias de narcotráfico y de seguridad fueron los temas principales en la agenda de comunicación para el gobierno y para los medios de comunicación.

La base de datos consta de 775 noticias relacionadas con la guerra contra las drogas en México. El total se analizaron más de 1.600 hojas de papel. Estas noticias fueron reportadas en los tres periódicos durante los dos períodos de tiempo mencionados. En The New York Times se encontraron 76 noticias para el primer período de tiempo en comparación con 45 para el segundo período. En The Guardian 41 noticias para el primer período de tiempo, mientras 23 para el segundo período. En El País 70 para el primer período de tiempo, mientras 77 para el segundo período. Y en El Universal se recolectaron 309 historias noticiosas para el primer período de tiempo, pero 134 para el segundo período.

En total, 496 historias noticiosas se obtuvieron del primer período de tiempo, el del ex presidente Felipe Calderón, mientras que sólo 279 del segundo período, el que corresponde al presidente electo Enrique Peña Nieto. Las noticias variaron entre reportes de noticias, entrevistas, columnas, reportajes y editoriales.

Debido a la amplia cantidad de temas en ámbitos distintos, y con el fin de catalogar las historias incluidas en los tres periódicos, la información fue clasificada en cinco macro-temas de acuerdo al evento o historia reportada. La clasificación está relacionada con: actos de infracción de la ley y los asuntos de justicia relacionados, sociedad civil, gobierno y política, los actos de violencia, y las historias de la gente y los escenarios relacionados con el estado de la situación.

Dentro de cada macro-tema se encuentran temas más específicos. En los actos de infracción de la ley y los asuntos de justicia relacionados se incluyen las noticias sobre el lavado de dinero, tráfico de armas, los casos de corrupción, la detención o la extradición de los presuntos delincuentes. En los asuntos de la sociedad civil, las no- 
ticias incluyeron temas de las víctimas y la violencia contra la sociedad civil, la vida cotidiana de las regiones o ciudades afectadas por el conflicto, la cultura popular, los medios sociales, el trabajo de las organizaciones no gubernamentales y las opiniones con respecto a la legalización de las drogas y el conflicto. Las noticias relacionadas al gobierno y la política se centraron en las estrategias y políticas del gobierno mexicano, legalización de las drogas, la relación México-Estados Unidos, y las elecciones presidenciales.

El cuarto macro-tema incluye los informes sobre actos de violencia tales como: lucha entre los cárteles, las bajas, las operaciones de las fuerzas de seguridad contra los cárteles y las amenazas y ataques contra los medios de comunicación y periodistas. Debido a la naturaleza del conflicto, esta categoría se consideró aparte de la de los actos de infracción de la ley en el sentido de que la violencia de los actos cometidos por los cárteles han tomado la atención de los medios de comunicación en México y otros países. El quinto macro-tema consiste en su mayoría de las historias de los miembros de los cárteles, periodistas y población civil como actores individuales.

Los casos fueron analizados en base a los eventos cubiertos. Los eventos cubiertos se utilizaron para identificar diferencias y similitudes en las temáticas. Puesto que no había casos como consecuencia del desarrollo del mismo incidente, se decidió catalogar cada uno de ellos en diferentes temas. Luego, estos temas fueron codificados en términos de los casos que hablaban de ellos y los atributos que se les prestan. Finalmente, también se analizaron los casos en términos de los contextos implicados en el contenido de las historias de noticias.

\section{Resultados}

El criterio de análisis de los datos tiene que ver con un tipo de aproximación deductiva. Es decir, los resultados son reportados con bases en la generalidad y la especificidad de las temáticas tratadas en los periódicos. Con las siguientes subsecciones se pretende responder a las interrogantes que dieron origen a la presente investigación. Las subsecciones tienen que ver con la identificación de temáticas particulares y generales en las historias noticiosas de los tres periódicos. Con la vinculación del término "guerra contra las drogas" a las realidades políticas y sociales del país en las que se reportan. Y con la influencia de actores principales en la manera de construir las historias noticiosas.

La primer subsección contiene la clasificación de las historias noticiosas por macro-tema. Y el análisis de correspondencia de dichas historias por macro-tema en distinto período presidencial. La subsección que sigue contabiliza y muestra las similitudes y diferencias entre las temáticas tratadas en los periódicos de The Guardian, The New York Times y El País. Además de señalar las temáticas relacionados al contexto inmediato local. La subsección final se preocupa por vislumbrar los actores implicados en las historias noticias y la manera en que éstos adaptan en sus prácticas discursivas la información proporcionada por los medios. 


\subsection{Diferencias y similitudes en temáticas generales}

Tabla 1: Desglose de las noticias por macro-tema

\begin{tabular}{|c|c|c|c|c|c|c|c|}
\hline & & & \multicolumn{4}{|c|}{ Periódico } & \multirow[b]{2}{*}{ Total } \\
\hline & & & $\begin{array}{c}\text { The New York } \\
\text { Times }\end{array}$ & The Guardian & El Pais & El Universal & \\
\hline \multirow[t]{10}{*}{ Macro-tema } & Asuntos de Justicia & Recuento & 39 & 25 & 39 & 137 & 240 \\
\hline & & $\%$ dentro del periódico & $32,2 \%$ & $39,1 \%$ & $26,5 \%$ & $30,9 \%$ & $31,0 \%$ \\
\hline & Sociedad Civil & Recuento & 20 & 5 & 43 & 107 & 175 \\
\hline & & $\%$ dentro del periódico & $16,5 \%$ & $7,8 \%$ & $29,3 \%$ & $24,2 \%$ & $22,6 \%$ \\
\hline & Asuntos de Política & Recuento & 43 & 10 & 25 & 91 & 169 \\
\hline & & $\%$ dentro del periódico & $35,5 \%$ & $15,6 \%$ & $17,0 \%$ & $20,5 \%$ & $21,8 \%$ \\
\hline & Actos de Violencia & Recuento & 9 & 12 & 27 & 90 & 138 \\
\hline & & $\%$ dentro del periódico & $7,4 \%$ & $18,8 \%$ & $18,4 \%$ & $20,3 \%$ & $17,8 \%$ \\
\hline & Historias Individuales & Recuento & 10 & 12 & 13 & 18 & 53 \\
\hline & & $\%$ dentro del periódico & $8,3 \%$ & $18,8 \%$ & $8,8 \%$ & $4,1 \%$ & $6,8 \%$ \\
\hline \multirow[t]{2}{*}{ Total } & & Recuento & 121 & 64 & 147 & 443 & 775 \\
\hline & & $\%$ dentro del periódico & $100,0 \%$ & $100,0 \%$ & $100,0 \%$ & $100,0 \%$ & $100,0 \%$ \\
\hline
\end{tabular}

Al comienzo de la investigación se planteó identificar similitudes y diferencias en las temáticas generales de las historias noticiosas de los tres periódicos internacionales en relación al conflicto de drogas en México. The Guardian, en este sentido, presenta una mayor proporción de historias periodísticas relacionadas a los asuntos de justicia (39.1\% del total de notas), que el periódico El Universal (30.9\% del total de notas) (Ver Tabla 1). Otro dato interesante es que El País presenta una mayor proporción de historia periodísticas relacionadas a la sociedad civil, 29.3\% del total de notas, que el periódico El Universal, 24.2\% del total de notas.

En los asuntos de política, The New York Times presenta una mayor proporción de historias periodísticas, $35.5 \%$ del total de notas, debido a la relación bilateral entre el gobierno Mexicano y el Estadounidense. Y a la atención especial por parte del gobierno Estadounidense en la franja fronteriza y sus ciudadanos en todo México. En este tema, El Universal registra una proporción de $20.5 \%$ del total de sus notas. Finalmente, en los actos de violencia, The Guardian, El Pais y El Universal registraron más o menos la misma proporción de historias periodísticas, $18.8 \%, 18.4 \%$ y $20.3 \%$ respectivamente. Sin considerar que cada uno de ellos registro en número total de notas las siguientes cifras: 12 el The Guardian, 27 El País, y 90 notas El Universal.

\subsection{Diferencias y similitudes de las temáticas generales en el período de transi- ción política del 2012 en el gobierno Mexicano}

Tabla 2 y Figura 1: Primer período correspondiente al gobierno de Felipe Calderón Hinojosa

\begin{tabular}{|lll|r|r|r|r|r|}
\hline & & \multicolumn{3}{|c|}{ Periódico } & \\
\cline { 3 - 7 } & & & \multicolumn{2}{|c|}{ The New York } \\
& & Times & The Guardian & El Pais & El Universal & Total \\
\hline Macro-tema & Asuntos de Justicia & Recuento & 28 & 18 & 24 & 126 & 196 \\
& & \% dentro de Periódico & $36.8 \%$ & $43.9 \%$ & $34.3 \%$ & $40.8 \%$ & $39.5 \%$ \\
\cline { 2 - 7 } & Sociedad Civil & Recuento & 9 & 4 & 16 & 65 & 94 \\
& \% dentro de Periódico & $11.8 \%$ & $9.8 \%$ & $22.9 \%$ & $21.0 \%$ & $19.0 \%$ \\
\cline { 2 - 7 } & Asuntos de Política & Recuento & 26 & 4 & 10 & 56 & 96 \\
& \% dentro de Periódico & $34.2 \%$ & $9.8 \%$ & $14.3 \%$ & $18.1 \%$ & $19.4 \%$ \\
\cline { 2 - 7 } & Actos de Violencia & Recuento & 7 & 10 & 14 & 53 & 84 \\
& \% dentro de Periódico & $9.2 \%$ & $24.4 \%$ & $20.0 \%$ & $17.2 \%$ & $16.9 \%$ \\
\cline { 2 - 7 } & Historias Individuales & Recuento & 6 & 5 & 6 & 9 & 26 \\
& & \% dentro de Periódico & $7.9 \%$ & $12.2 \%$ & $8.6 \%$ & $2.9 \%$ & $5.2 \%$ \\
\hline Total & & Recuento & 76 & 41 & 70 & 309 & 496 \\
& & \% dentro de Periódico & $100.0 \%$ & $100.0 \%$ & $100.0 \%$ & $100.0 \%$ & $100.0 \%$ \\
\hline
\end{tabular}




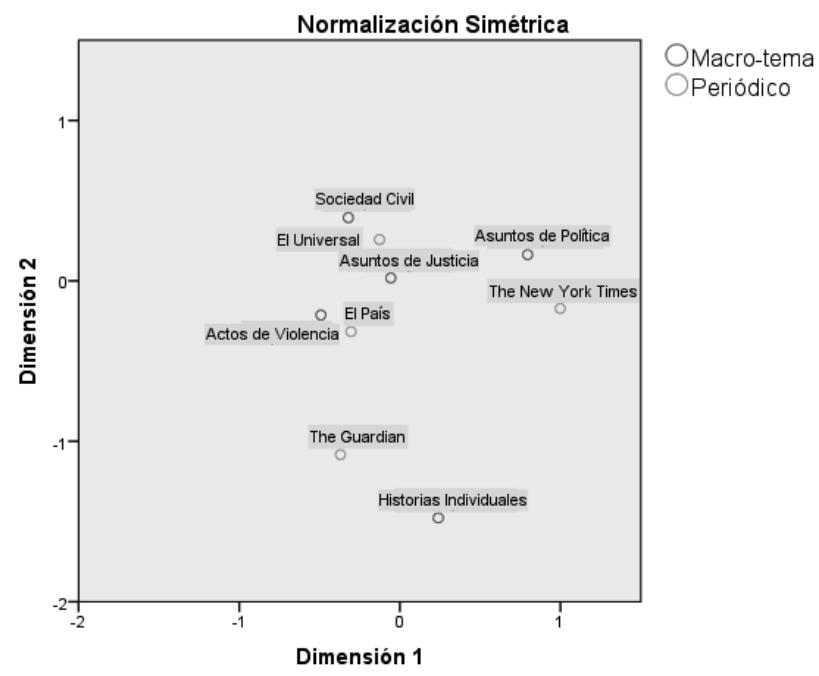

Tabla 3 y Figura 2: Segundo período correspondiente al gobierno de Enrique Peña Nieto

\begin{tabular}{|c|c|c|c|c|c|c|c|}
\hline & & & \multicolumn{4}{|c|}{ Periódico } & \multirow[b]{2}{*}{ Total } \\
\hline & & & $\begin{array}{c}\text { The New York } \\
\text { Times }\end{array}$ & The Guardian & El País & El Universal & \\
\hline \multirow[t]{10}{*}{ Macro-tema } & Asuntos de Justicia & Recuento & 11 & 7 & 15 & 11 & 44 \\
\hline & & $\%$ dentro de Periódico & $24.4 \%$ & $30.4 \%$ & $19.5 \%$ & $8.2 \%$ & $15.8 \%$ \\
\hline & Sociedad Civil & Recuento & 11 & 1 & 27 & 42 & 81 \\
\hline & & $\%$ dentro de Periódico & $24.4 \%$ & $4.3 \%$ & $35.1 \%$ & $31.3 \%$ & $29.0 \%$ \\
\hline & Asuntos de Política & Recuento & 17 & 6 & 15 & 35 & 73 \\
\hline & & \% dentro de Periódico & $37.8 \%$ & $26.1 \%$ & $19.5 \%$ & $26.1 \%$ & $26.2 \%$ \\
\hline & Actos de Violencia & Recuento & 2 & 2 & 13 & 37 & 54 \\
\hline & & \% dentro de Periódico & $4.4 \%$ & $8.7 \%$ & $16.9 \%$ & $27.6 \%$ & $19.4 \%$ \\
\hline & Historias Individuales & Recuento & 4 & 7 & 7 & 9 & 27 \\
\hline & & $\%$ dentro de Periódico & $8.9 \%$ & $30.4 \%$ & $9.1 \%$ & $6.7 \%$ & $9.7 \%$ \\
\hline \multirow[t]{2}{*}{ Total } & & Recuento & 45 & 23 & 77 & 134 & 279 \\
\hline & & \% dentro de Periódico & $100.0 \%$ & $100.0 \%$ & $100.0 \%$ & $100.0 \%$ & $100.0 \%$ \\
\hline
\end{tabular}

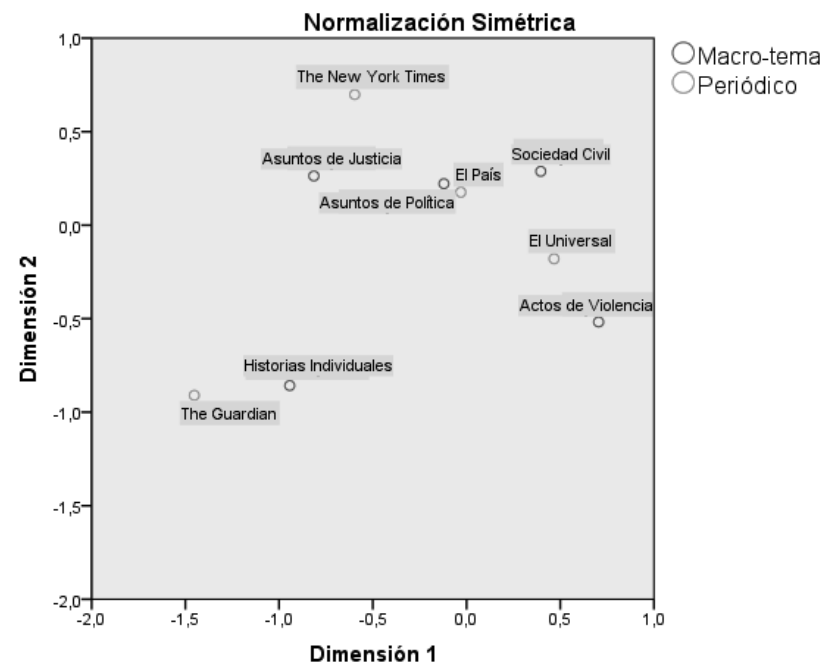


El análisis de las historias periodísticas también se centró en identificar las diferencias y similitudes de las temáticas generales en el período de transición política. Todo esto con el objetivo de registrar posibles variaciones en la agenda temática de los medios en uno y otro período; el de Felipe Calderón Hinojosa y el de Enrique Peña Nieto respectivamente. En ese sentido, las variaciones son evidentes. En principio se muestra una clara distinción en la cobertura periodística del fenómeno durante ambos periodos. En el primer período, se registra un número total de historias periodísticas de 495; mientras que en el período de Enrique Peña Nieto tan solo se registran 279 historias (Ver Tabla 2 y 3 ).

Las historias relacionadas a los asuntos de política parecen ser una constante en ambos períodos en The New York Times (Ver Tabla 2 y 3 ). No obstante, hay una tendencia más clara de estas historias en el período de Felipe Calderón que en el período de Enrique Peña Nieto (Ver Figura 1). En el período de Enrique Peña Nieto The New York Times tiende a reportar más historias relacionadas a asuntos de justicia (Ver Figura 2).

A pesar de que la proporción de historias periodísticas relacionadas a actos de violencia en The Guardian durante el período de Felipe Calderón sobresale, y se asemeja mucho, a la proporción de historias del periódico El Universal en el período de Enrique Peña Nieto, $24.4 \%$ y $27.6 \%$ del total de notas respectivamente (Ver Tabla 2 y 3 ), en el período de Enrique Peña Nieto la tendencia es que el periódico El Universal reporte historias de este tipo (Ver Figura 2). El País, en ese sentido, tiende a reportar más historias de actos de violencia durante el período de Felipe Calderón (Ver Figura 1).

Finalmente, a pesar de que la proporción de historias individuales es mayor en el periódico The Guardian durante el período de Enrique Peña Nieto que durante el período de Felipe Calderón, 30.4\% y 12.2\% del total de notas respectivamente, en ambos periodos este periódico tiende a reportar historias individuales de miembros de carteles, periodistas o población civil (Ver Figura 1 y 2).

\subsection{Diferencias y similitudes en temáticas específicas y vinculación del término "guerra contra las drogas" a las realidades políticas y sociales nacionales de los periódicos analizados}

Figura 3: Diferencias y similitudes en temáticas específicas entre los tres periódicos internacionales (\%)

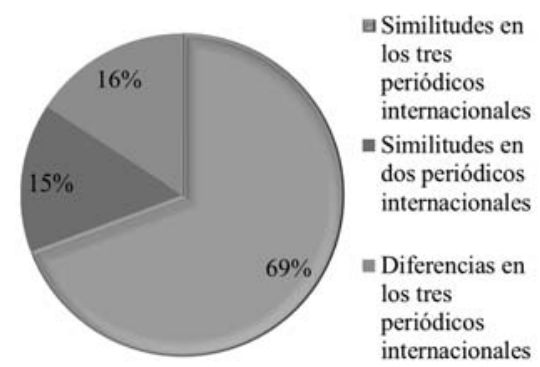

Otra de las encomiendas del presente análisis es identificar las similitudes y las diferencias en las temáticas específicas de los periódicos internacionales en los dos períodos de tiempo. Además, se identifica si el término guerra contra las drogas, dentro del contexto de las notas referentes a México, se encuentra vinculado en las historias 
recolectadas a las realidades políticas y sociales del país de origen de cada uno. Por un lado, el 69\% de las temáticas contabilizadas se encuentra inscrito en las historias de los tres periódicos mencionados. Mientras que el 15\% solamente se encuentra en dos, y el $16 \%$ corresponde a temáticas singulares de cada periódico (Ver Figura 3). Lo cual acentúa una fuerte homogenización de las temáticas reportadas para el periodo analizado.

Por otro lado, si se analizan las temáticas específicas en relación a la proporción de historias por periódico, se encuentran principalmente cinco eventos clave: el abatimiento del presunto líder del cartel de los Zetas, Heriberto Lazcano; el caso de corrupción del General Dauahare; el lavado de dinero en el banco HSBC; el blog del narco; y la operación "rápido y furioso" (Ver Figura 4).

Figura 4: Diferencias en temáticas específicas entre los tres periódicos internacionales (\%)

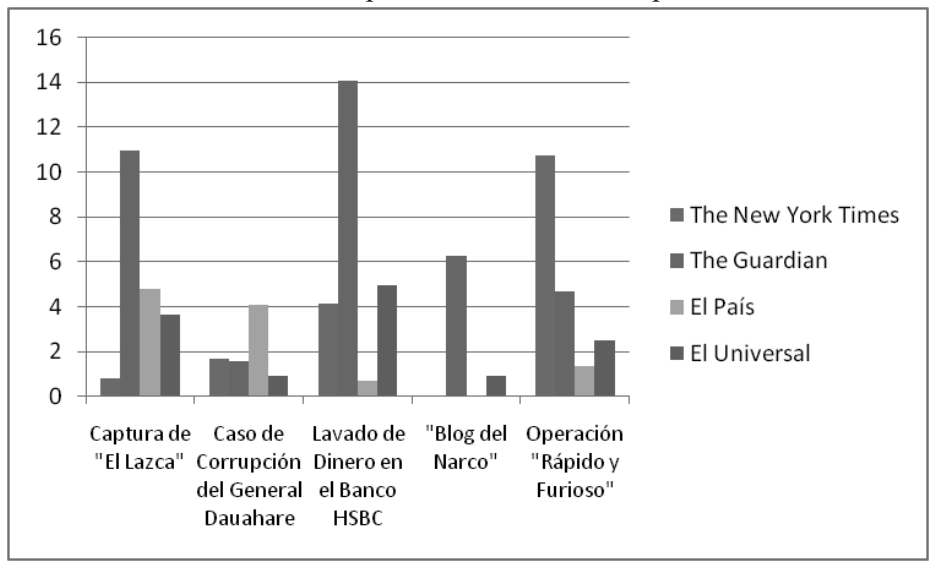

En la mayoría de estos casos los eventos fueron reportados por una notable proporción de historias periodísticas. Los eventos de "El Lazca", el lavado de dinero y el "Blog del Narco" son singulares porque todos ellos llamaron la atención constante del periódico The Guardian. Los eventos del lavado de dinero en el banco HSBC y el "blog del narco" son relevantes ya que constituyen la conexión entre el evento global con el interés local. El banco HSBC, en ese sentido, está legalmente constituido en el Reino Unido, por lo que cualquier acción o evento internacional en el que se vea involucrado incumbe a la nación como tal. El "blog del narco", por otro lado, muestra un notable incremento en su nivel de importancia para el contexto editorial de este periódico a raíz de una entrevista realizada a los creadores de esta página y su posterior salida de México (Carroll, 2013; El Universal, 2013).

El caso de corrupción del general Dauahare en el periódico El País es interesante. Si bien no se encuentra situado en un macro tema con grandes proporciones de historias periodísticas, asuntos de justicia (Ver Tabla 1), sí representa una notable constante en proporción de historias como evento dentro de El País respecto a otros periódicos (Ver Figura 4). Esta temática constituye casi un 4\% del total de sus notas.

En el caso de este periódico español, destacan el mayor número de notas en el año analizado en relación a los otros dos periódicos. Esta situación puede tener dos lectu- 
ras. La primera es la presencia del grupo propietario de este periódico en México, a través de alianzas y negocios en los medios de comunicación nacionales. La otra lectura se refiere a la proximidad cultural de los dos estados-nación. Cabe resaltar que la única referencia directa del conflicto en México, en relación al contexto nacional de España, fue el arresto de presuntos miembros del Cártel de Sinaloa en Madrid en Agosto del año 2010. Lo cual fue reportado por el propio periódico como un intento de presencia de esta organización criminal en este país.

\section{Conclusiones}

Con base a los resultados del presente trabajo de investigación, se concluye que si bien las notas periodísticas durante el período analizado tienen una afinidad temática, hay una diferenciación y domesticación del hecho noticioso a los contextos particulares de los periódicos analizados. Las historias identificadas en las temáticas generales y particulares dentro de las categorías por macro-tema demuestran, por un lado, un perfil editorial de cada periódico al mismo contexto noticioso. Por otro lado, se observa una diferente jerarquización con respecto al interés nacional que el propio periódico cree que se relaciona con la agenda pública local.

En el contexto de la "guerra contra las drogas", el primer nivel de la agenda- setting (Weaver, McCombs, y Shaw, 2004) se refiere a la relación de este término con hechos, eventos o temáticas dentro de los mensajes periodísticos. En las historias noticiosas de los tres periódicos internacionales se identificaron más de treinta temáticas específicas de las cuales algunos casos constituyen hechos que se encuentran relacionados con la nación de origen del periódico. Los hechos de los que se habla son el lavado de dinero en el Banco HSBC, el "Blog del Narco" y la operación rápido y furioso.

Por tal motivo, se puede hablar de una influencia de la agenda por parte del estadonación de donde se genera el material noticioso, en este caso México, pero de una relación del hecho a preocupaciones locales. En el caso del lavado del dinero con la política interior del Reino Unido y Estados Unidos, y en el caso de la operación conocida como "rápido y furioso" con la Agencia de Alcohol, Tabaco, Armas de Fuego y Explosivos (ATF, por sus siglas en inglés) de Estados Unidos.

Es interesante distinguir, por otro lado, que la aproximación teórica de agendasetting dice que la agenda de un medio influye más allá del debate mediático y tiene influencia en las políticas públicas de un lugar (Weaver, McCombs, y Shaw, 2004). En el caso de la "guerra al narcotráfico", sin embargo, la iniciativa fue originada por un estado-nación, Estados Unidos. La política como tal fue implementada en los casos Colombia y México, y el concepto fue mediatizado fuera del contexto local, encontrando un uso distinto en diferentes medios de comunicación internacional. En este caso, el término mediático de la guerra contra las drogas, tomado como referencia a una política pública, fue difundido en los periódicos The Guardian, The New York Times, El País y El Universal. Lo cual querría decir que la agenda mediática no solamente influye en la política pública de un determinado país sino también a la inversa.

Una de las coincidencias muy marcadas se refiere a la homogenización de temáticas de las historias noticiosas. Quizá las proporciones de cobertura cambian de un medio a otro, pero es evidente como cada periódico internacional se preocupa por el 
hecho. Las historias en cada periódico son distintas, pero las temáticas de las historias son las mismas para cada lugar. Lo cual parece indicar una cultura del mundo (Lechner y Boli, 2005) emergente respecto a la proporción de temáticas de las historias noticiosas, pero una diversidad cultural dislocada en la manera de domesticar (Gurevitch, Levy, y Roch, 1991) los hechos por cada periódico en lo local.

\section{Referencias bibliográficas}

ALASUUTARI, Pertti; QADIR, Ali; \& CREUTZ Karin (2013): “The Domestication of Foreign News: News Stories Related to the 2011 Egyptian Revolution in British, Finnish and Pakistani Newspapers" Media, Culture \& Society, vol. 35, n. 6, pp.692707.

APPADURAI, Arjun (1990): "Disjuncture and difference in the global cultural economy", Public Culture, vol.2, n.2, pp. 1-24.

BENTON, Marc \& FRAZIER Jean (1976): "The Agenda Setting Function of the Mass Media at Three Levels of "Information Holding". Communication Research, vol. 3, n. 3, pp.261- 274.

CARROLL, Rory (2013): "Blog del Narco: author who chronicled Mexico's drugs war forced to flee" en The Guardian, 16 de Mayo 2013, sección World News: http://www.theguardian.com/world/2013/may/16/blog-del-narco-mexico-drug-war. [Consulta: 7 de Marzo 2014].

CLAUSEN, Lisbeth (2004): "Localizing the Global: 'Domestication' Processes in International News Production". Media, Culture \& Society, pp. 25-45.

COLEMAN, Renita; McCOMBS, Maxwell; SHAW, Donald; \& WEAVER David (2009): "Agenda Setting". En WAHL-JORGENSEN, Karin \& HANITZSCH, Thomas (eds.): Handbook of Journalism Studies. London, Routledge, pp. 147-160.

DAI, Jia \& HYUN, Kideuk (2010): "Global risk, domestic framing: coverage of the North Korean nuclear test by US, Chinese, and South Korean news agencies". Asian Journal of Communication, vol. 20, n. 3, pp. 299-317.

EIDE, Elisabeth \& YTTERSTAD, Andreas (2011): “The Tainted Hero: Frames of Domestication in Norwegian Press Representation of the Bali Climate Summit". The International Journal of Press/Politics, vol. 16, n. 1, pp. 50-74.

FISHER, Gary (2006): Rethinking our War on Drugs. Connecticut, Praeger.

FUNKHOUSER, Ray \& McCOMBS Maxwell (1971): "The Rise and Fall of News Diffusion”. The Public Opinion Quaterly, vol. 35, n. 1, pp. 107-113.

GUO, Leo; HONG, Tien Vu; \& McCOMBS, Maxwell (2012): “An Expanded Perspective on Agenda- Setting Effects. Exploring the third level of agenda setting". Revista de Comunicación, vol. 11, pp. 51- 68.

GUREVITCH, Michael; LEVY, Mark \& ROEH, Itzhak (1991): “The Global Newsroom: Convergences and Diversities in the Globalization of Television News". En DAHLGREN, Peter \& SPARK, Collin (eds.): Communication and Citizenship: 
Journalism and the Public Sphere in the New Media Age. London, Routledge, pp. 195-216.

HANDLEY, Robert \& ISMAIL, Amani (2010): “Territory under siege: 'their' news, 'our' news and 'ours both' news of the 2008 Gaza crisis". Media, War \& Conflict, vol. 3, n.3, pp. 279-97.

HERNÁNDEZ, Roberto; FERNÁNDEZ-COLLADO, Carlos; y BAPTISTA Pilar (2006): Metodología de la Investigación. Cuarta Edición. México, McGraw-Hill Interamericana.

IGLESIAS, Ángel (2013): "Spectatorship and visual evidence of violence in Mexico: When the right to information becomes exploitation" Revista Redes.Com, n. 8, pp. 246-231.

ISMAIL, Amani (2010): "Making Sense of a Barrier: U.S. News Discourses on Israel's Dividing Wall". Journal Of Communication Inquiry, vol. 34, n. 1, pp: 85-108.

KIHAM, Kim \& McCOMBS, Maxwell (2007): "News Story Descriptions and the Public's Opinions of Political Candidates". Journalism and Mass Communication Quarterly, vol. 84, n. 2, pp. 299-314.

KRIPPENDORF, Klaus (2004): Content Analysis. An Introduction to Its Methodology. London, Sage Publications.

LACASSE, Katherine \& FORSTER, Larissa (2012): "The War Next Door: Peace Journalism in US Local and Distant Newspapers' coverage of Mexico". Media, War \& Conflict, vol. 5, n. 3, pp. 223-237.

LECHNER, Frank \& BOLI, John (2005): World Culture: Origins and Consequences. Oxford, Blackwell Publishing.

LEE, Chin Chuan; PAN, Zhongdang; MAN CHAN, Joseph; \& SO, Clement Ya Ko (2001): "Through the Eyes of U.S. Media: Banging the Democracy Drum in Hong Kong". Journal of Communication, vol. 51, n. 2, pp. 345-365.

LIEBES, Tamar (1992): "Our War/ Their War: Comparing the Intifadeh and the Gulf War on U.S. and Israel Television". Critical Studies in Mass Communication 9, vol. 9, n. 1, pp. 44-55.

MARTÍNEZ, Francisco Javier; LOZANO RENDON, José Carlos; y RODRIGUEZ ELIZONDO, Fernando Abiel (2012): "Cobertura de la violencia y la cultura de la legalidad en los medios fronterizos México- Estados Unidos de Norteamérica" ANAGRAMAS, vol. 11, n. 21, pp. 21-40.

McCOMBS, Maxwell \& SHAW, Donald (1972): "The Agenda-Setting Function of Mass Media”. The Public Opinion Quaterly, vol. 36, no. 2, pp. 176-187.

McCOMBS, Maxwell \& GHANEM, Salma (2001): "The Convergence of Agenda Setting and Framing". en rEESE, S., O. Gandy y GRANT A. (eds.): Framing Public Life. London, Lawrence Erlbaum Associates, Publishers, pp. 67-81.

McLEOD, Jack; BECKER, Lee; \& BYRNES, James (1974): “Another Look at the Agenda-setting Function of the Press". Communication Research, pp. 131-166. 
MEYER, José Antonio y MIRANDA, Gabriel (Coords., 2013): Comunicación política y seguridad pública en México. La laguna, Tenerife, España: Cuadernos Artesanos de Latina/ 36.

NOSSEK, Hillel (2004): "Our News and their News" Journalism, vol. 5, no. 3, pp: 343-68.

QADIR, Ali \& ALASUUTARI, Pertti (2013): "Taming terror: domestication of war on terror in the Pakistan media". Asian Journal of Communication, vol. 6, no. 8, pp. 575-589.

REDACCIÓN UNIVERSAL (2013): "Huye de México autora de Blog del narco: The Guardian", en El Universal, 17 Mayo 2013, sección Estados, http://www.eluniversal.com.mx/notas/923645.html. [Consulta 3 de marzo 2014].

RIFFE, Daniel; LACY, Stephen; \& FICO, Frederick (2005): Analyzing Media Messages. London, Lawrence Erlbaum Associates, Publishers.

ROBERTSON, Roland (1992): Globalisation, Social Theory and Global Culture. London, Sage.

SÁNCHEZ, Citlalli (2013): "La cultura de la legalidad y su cobertura en la prensa nacional mexicana". Nómadas. Revista Crítica de Ciencias Sociales y Jurídicas, Número Especial: América Latina.

SCHEUFELE, Dietram A. \& TEWKSBURY, David (2007): "Framing, Agenda Setting, and Priming: The Evolution of Three Media Effects Models". Journal of Communication, vol. 57, no. 1, pp. 9-20.

SEI-HILL, Kim; SHEUFELE, Dietram; \& SHANAHAN, James (2002): “Think about it this way: Attribute agenda-setting function of the Press and the Public's Evaluation Of a Local Issue". Journalism and Mass Communication Quarterly, vol. 79, no. 1, pp. 7-25.

TAN, Yuen \& WAVER, David (2013): "Agenda Diversity and Agenda Setting From 1956 to 2004". Journalism Studies, vol. 14, n. 6, pp. 773-789.

VALENZUELA, Sebastian \& McCOMBS, Maxwell (2007): “Agenda-setting effects on vote choice: Evidence from the 2006 Mexican Election". International Communication Association 57th Annual Conference. San Francisco, California.

WALLERSTEIN, Immanuel (2004): Geopolitica y Geocultura. Ensayos sobre el moderno sistema mundial. Barcelona \& Capellades, Editorial Kairós.

WEAVER, David; McCOMBS, Maxwell; \& SHAW Donald (2004): “Agenda-Setting Research: Issues, Attributes, and Influences". En KAID, Lynda (ed.): Handbook of Political Communication Research. London, Lawrence Erlbaum Associates, Publishers, pp. 257-282. 